\title{
Feasibility of and barriers to thalassemia screening in migrant populations: a cross- sectional study of Myanmar and Cambodian migrants in Thailand
}

Julia Z. Xu ${ }^{1,2^{*}}$, Wilaslak Tanongsaksakul ${ }^{3}$, Thidarat Suksangpleng ${ }^{4}$, Supachai Ekwattanakit ${ }^{4}$, Suchada Riolueang ${ }^{4}$, Marilyn J. Telen ${ }^{1}$ and Vip Viprakasit ${ }^{4,5,6^{*}}$

\begin{abstract}
Background: Thalassemia, an inherited hemoglobin disorder, has become a global public health problem due to population migration. Evidence-based strategies for thalassemia prevention in migrants are lacking. We characterized barriers to thalassemia screening and the burden of thalassemia in migrant workers in Thailand.

Methods: Multilingual demographic and KAP surveys were completed by 197 Thai, 119 Myanmar, and 176 Cambodian adults residing in Thailand. Thalassemia awareness, socio-demographic predictors, and knowledge and attitude scores were compared between migrant and Thai subjects. Comprehensive thalassemia testing was performed for migrants.

Results: Migrants had extremely poor thalassemia awareness (4.1\%) compared to Thai subjects (79.6\%) and had lower thalassemia knowledge scores but similar attitude scores. Surveys identified differing sociodemographic factors predicting awareness in Thai and migrant subjects, as well as key misconceptions likely to hinder thalassemia screening uptake. Nearly all migrants consented to thalassemia testing. We identified abnormal hemoglobin profiles in $52.7 \%$ of migrants and a higher projected rate of severe thalassemia births in migrants.
\end{abstract}

Conclusions: The high burden of thalassemia and tremendous knowledge gap in migrants needs urgent attention. Thalassemia screening was feasible and acceptable in our migrant population. Sociocultural and structural barriers merit further attention when designing thalassemia screening and prevention policies for migrants in Thailand and globally.

Keywords: Thalassemia, Hemoglobin E, Migrants, Awareness, KAP survey, Cross-cultural comparison, Epidemiology, Genetic testing, Thailand, Southeast Asia

\footnotetext{
*Correspondence: Julia.xu2@nih.gov; vip.vip@mahidol.edu

'Department of Medicine, Duke University, Durham, USA

${ }^{4}$ Thalassemia Center, Faculty of Medicine Siriraj Hospital, Mahidol University,

2 Wanglang Road, Bangkoknoi, Bangkok 10700, Thailand

Full list of author information is available at the end of the article
}

(C) The Author(s). 2021 Open Access This article is licensed under a Creative Commons Attribution 4.0 International License, which permits use, sharing, adaptation, distribution and reproduction in any medium or format, as long as you give appropriate credit to the original author(s) and the source, provide a link to the Creative Commons licence, and indicate if changes were made. The images or other third party material in this article are included in the article's Creative Commons licence, unless indicated otherwise in a credit line to the material. If material is not included in the article's Creative Commons licence and your intended use is not permitted by statutory regulation or exceeds the permitted use, you will need to obtain permission directly from the copyright holder. To view a copy of this licence, visit http://creativecommons.org/licenses/by/4.0/. The Creative Commons Public Domain Dedication waiver (http://creativecommons.org/publicdomain/zero/1.0/) applies to the data made available in this article, unless otherwise stated in a credit line to the data. 


\section{Background}

Thalassemia syndromes, caused by impaired $\alpha$ - and/or $\beta$-globin chain synthesis, together with sickle cell disease represent the most common human Mendelian disorders. There are an estimated 56,000 annual births globally with severe thalassemia (hemoglobin [Hb] Bart's hydrops fetalis, $\mathrm{Hb} \mathrm{H}$ disease, $\beta$-thalassemia major, and $\mathrm{Hb} E / \beta$-thalassemia) [1], though the burden of all clinically significant thalassemia disease likely far exceeds this estimate. Due to increasing international migration, the epidemiology of hemoglobin disorders is changing rapidly, and the resulting new challenges posed to health services have been recognized in Europe and the United States [2-4]. Southeast Asia (SEA) is severely affected by thalassemia syndromes [5], with high frequencies of both $\alpha$ - and $\beta$-thalassemia, including $\mathrm{Hb}$ E ( $\beta 26$ Glu $\rightarrow$ Lys), a structural variant that reduces $\beta$-globin expression (Table 1).

Thailand has one of the highest burdens of thalassemia in the world, with $\sim 15$ million carriers and 50,000 pregnancies at risk annually for severe thalassemia [11]. Thailand is also one of the few SEA countries with effective severe thalassemia prevention and control policies, focusing on public education, prenatal screening, and prenatal diagnosis. This has led to a decreased incidence of severe thalassemia syndromes, including $\mathrm{Hb}$ Bart's hydrops fetalis [11]. Concurrently, Thailand's relatively prosperous and stable economy has encouraged increasing migration from neighboring countries, with 2.4 million migrant workers from Myanmar, Cambodia, and Laos [12, 13]. These three neighboring countries are also estimated to have a high prevalence of thalassemia and $\mathrm{Hb} \mathrm{E}$ (Table 1). However, they do not have national thalassemia education, screening, or counseling programs in place, and data on the incidence of severe thalassemia syndromes are limited due to lack of routine screening [14]. With increasing intra-regional migration, the lack of access to thalassemia-related services among migrant populations in Thailand not only hinders early diagnosis and treatment but also potentially undermines the Thai thalassemia program's long-term success. Anecdotally, a rise in the number of births affected by severe thalassemia among migrant couples has been observed (V. Viprakasit, personal communication, November 1, 2017).

Addressing the issue of thalassemia in migrant populations is therefore of utmost importance but fraught with challenges. Migrant workers are often low-skilled, enter through irregular channels, and have limited or no access to healthcare. There are also large populations of asylum seekers and refugees from Myanmar and other neighboring countries who have crossed the border into Thailand irregularly and reside in refugee camps and border towns. The lack of epidemiological data regarding disease burden in different migrant populations hinders policymakers' abilities to weigh the social benefit and economic cost of implementing thalassemia programs. Additionally, knowledge gaps and cultural differences are known barriers to the uptake of screening and the effectiveness of thalassemia prevention efforts [1517], yet few studies have examined knowledge, attitudes, and health-seeking behaviors among SEA migrants. How best to engage migrants in thalassemia education and screening and whether screening is feasible and acceptable to migrant populations must be explored.

We developed demographic and knowledge, attitudes, and practices (KAP) surveys to identify potential barriers to thalassemia screening among Myanmar and Cambodian migrant workers residing in Chonburi, an industrial province within the Eastern Economic Corredor (EEC), a major growing economic region in Thailand and home to one of the largest migrant worker populations in the country. We hypothesized that migrant subjects would have less awareness of thalassemia compared to Thai

Table 1 Carrier rates (in \%) for common hemoglobin disorders in Southeast Asia ${ }^{a}$

\begin{tabular}{lllll}
\hline Country & $\mathbf{a}^{\mathbf{0}}$-thalassemia (\%) & $\mathbf{a}^{+}$-thalassemia (\%) & $\beta$-thalassemia (\%) & Hemoglobin E (\%) \\
\hline Brunei [6, 7] & 0 & 4.3 & $2-22.7$ & $0-3.7$ \\
Cambodia & 1 & 15.5 & 2.8 & $10-54$ \\
Indonesia & $<1$ & $3-20$ & 3 & $1-33$ \\
Laos $[8,9]$ & $8.7-13.9$ & $11-17.7$ & $3.5-5$ & $22.9->30$ \\
Malaysia & 4.5 & 16 & 4.5 & $1-3$ \\
Myanmar & NA & 10 & $1-5.3$ & $4-48$ \\
Philippines & 5 & 2.2 & 1 & NA \\
Singapore & $2-3$ & $1-3$ & 0.93 & 0.64 \\
Thailand & $2.2-9$ & $8-30$ & $1-3$ & $10-50$ \\
Vietnam & NA & 3.5 & 4 & $10-20$ \\
\hline
\end{tabular}

"\%" refers to the percentage of individuals affected (i.e. \% carriers) within the population. NA Not available

adapted from Viprakasit et al., 2009 [10]. 
subjects and that knowledge would correlate with attitudes towards thalassemia screening and prevention. Furthermore, we performed comprehensive thalassemia testing to demonstrate the disease burden and assess the feasibility and acceptability of thalassemia screening in migrants. Novel insights from this study may inform regional migrant health policy and improve thalassemia education, prevention, and care for migrant populations globally.

\section{Methods}

\section{Study setting and population}

We performed a cross-sectional study of Myanmar and Cambodian migrant and Thai subjects of reproductive age (18-49 years) residing in Chonburi, from February to May 2018 at Laem Chabang Hospital (LCH), a secondary care center serving migrants in its catchment area under the Ministry of Public Health. Migrants were screened for eligibility at the time of presentation for health registration (either renewal or new registration), an annual prerequisite for obtaining a work permit and legal status. Thai subjects presenting for non-urgent outpatient care at LCH were screened for eligibility and used as a comparison population for surveys. Thai, Burmese, and Khmer language interpreters were used, and only subjects who spoke one of these languages were eligible. Those pregnant or with a pregnant partner by self-report were excluded. A total of 200 Thai and 300 migrant subjects were surveyed. A small number of subjects were lost before or after providing consent (Fig. 1). A lost subject was defined as an individual who initially agreed to participate in the study, but subsequently left the hospital before completing the study without alerting the study team of their withdrawal from the study; these individuals were excluded from the analysis.

\section{Survey development and administration}

Demographic and KAP surveys were developed using existing literature on thalassemia-related surveys [18-22] and expert opinion. Surveys were translated from English to Thai, Burmese, and Khmer and assessed for face and ethnographic validity by the research team and by Myanmar and Cambodian providers and interpreters (Appendix 1A-D in Additional file 1). "Nationality" was used in place of ethnicity due to the existence of ethnic minorities that complicate the definition of ethnicity. In assessing awareness of thalassemia, the medical term "thalassemia" was used, as no idiom or layman's term exists in Thai, Burmese, or Khmer based on expert opinion.

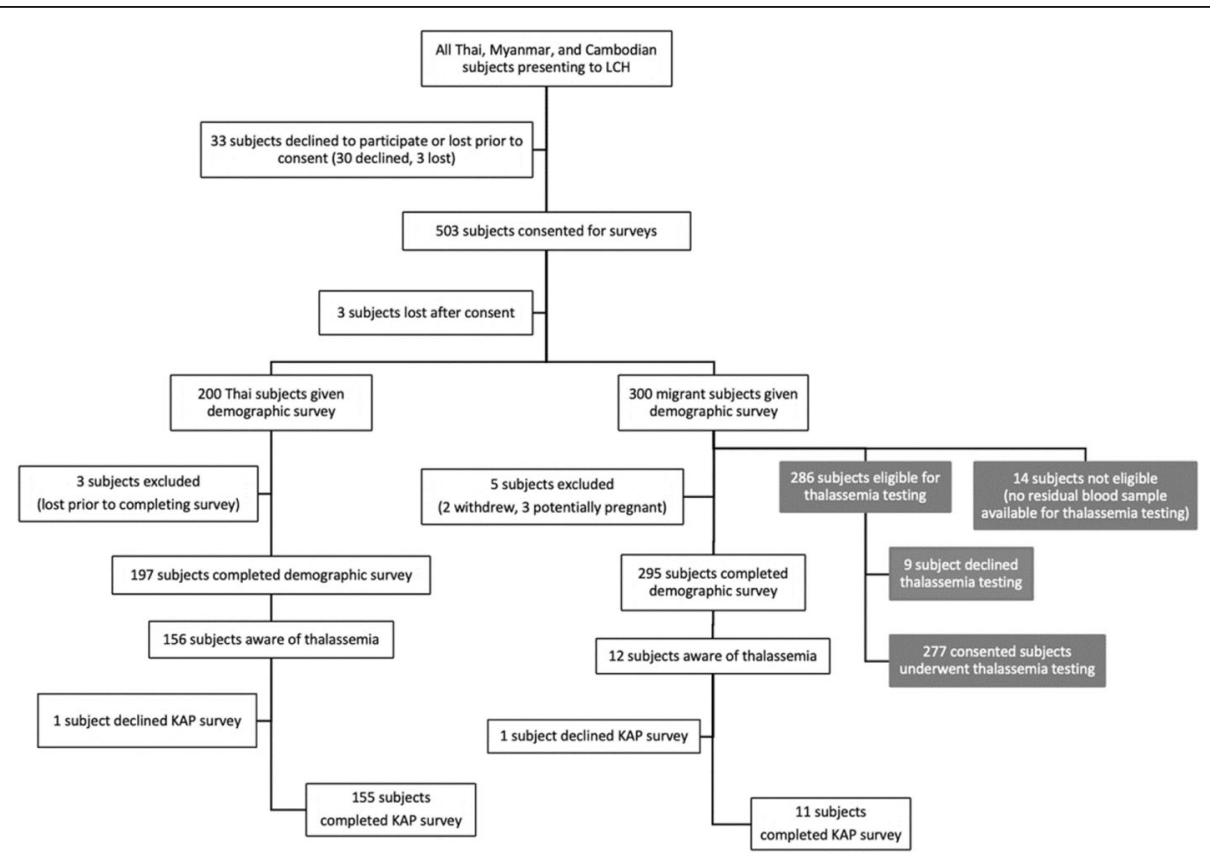

Fig. 1 CONSORT flow diagram for surveys and thalassemia testing (the latter in gray). Thai, Myanmar, and Cambodian subjects of reproductive age (18-49 years old) presenting to Laem Chabang Hospital $(\mathrm{LCH})$ were screened for eligibility. Those individuals who did not speak Thai, Burmese, or Khmer, or pregnant or with a pregnant partner by self-report, were excluded. Subjects were considered lost if they were approached by the study team and initially agreed to participate in the study, but subsequently left the hospital before completing the study without alerting the study team. Three subjects were lost prior to consent, 3 following consent and prior to starting the surveys, and 3 prior to completing the full demographic survey. Out of 200 Thai and 300 migrant subjects surveyed, 492 subjects completed the demographic survey. The KAP survey was completed by 155 Thai and 11 migrant subjects who were aware of thalassemia. Out of the 300 migrant subjects offered thalassemia testing, 286 were eligible for and 277 (96.9\%) consented to thalassemia testing 
Awareness of thalassemia was the primary outcome, with demographic characteristics, health-seeking behaviors, personal and family medical history, and awareness of anemia used as predictors. All subjects completed the 32-question demographic survey. Only subjects reporting awareness of thalassemia completed the 31-question KAP survey, consisting of three domains: 12 true-orfalse knowledge questions, 14 attitude questions based on a 5-point Likert scale, and five nested questions about practices surrounding thalassemia testing and reproduction (Appendix 2A-D in Additional file 1). Surveys were administered to the majority of migrants orally with interpreter assistance, due to lower rates of literacy compared to Thai subjects.

\section{Sample size calculation and statistical methods}

Based on published differences in awareness in migrants or ethnic minorities compared to natives [23], we hypothesized at least a $25 \%$ difference in thalassemia awareness between Thai and migrant subjects. Utilizing a sample size of 200 per group, we expected to achieve $95 \%$ power, assuming $\alpha=0.05$. We allowed for an increase in the enrollment target to 300 if $<30$ subjects (15\%) in either group completed the KAP survey.

Descriptive statistics were used to compare sociodemographic characteristics. Subgroup analyses for predictors of thalassemia awareness were performed in Thai and migrant subjects. Associations between awareness of thalassemia and predictors were assessed using ChiSquare analysis, Fisher's Exact Test, and univariate logistic regression. Descriptive statistics were used to compare individual KAP survey questions. The knowledge score reflected the number of correctly answered knowledge questions out of 12. Attitude questions were scored using the Likert scale, with inverse questions scored in reverse, and averaged to obtain an attitude score. Medians with inter-quartile ranges (IQR) were reported for knowledge and attitude scores, and nonparametric tests were used to compare medians between Thai and migrant groups. The correlation between knowledge and attitude scores was assessed using the Spearman correlation for non-parametric data. Cronbach's alpha was used to assess the internal reliability of both the knowledge and attitude sections. The level of statistical significance was set as $p<0.05$. All statistical analyses were performed using SAS software, version 9.4 (SAS Institute Inc., Cary, NC, USA).

\section{Laboratory and molecular testing for thalassemia}

Thalassemia testing was offered to migrants in a separate informed consent process after completion of surveys, so as not to bias subjects' perspective on thalassemia screening or awareness/knowledge. For all migrant subjects consenting to thalassemia testing, complete blood count $(\mathrm{CBC})$ was performed using an automated red blood cell counter (Sysmex F280, Sysmex, Tokyo, Japan), and $\mathrm{Hb}$ typing was performed by high-performance liquid chromatography (HPLC) using Variant II (Bio-Rad Laboratories, Hercules, CA, USA). Multiplex Gap-polymerase chain reaction $(\mathrm{PCR})$ and amplification-refractory mutation system-PCR assays for the detection of common $\alpha$ thalassemia mutations (listed in Table 2) was performed for all samples [24, 25], Hb E variants were identified by elevated $\mathrm{Hb} \mathrm{A}_{2} / \mathrm{E}$ by HPLC in the expected percent ranges for heterozygosity or homozygosity $\mathrm{Hb} \mathrm{E}(25-35 \%$ for $\mathrm{Hb} \mathrm{E}$ trait without $\alpha$-thalassemia; $15-20 \%$ for $\mathrm{Hb} \mathrm{E}$ trait with $\alpha$-thalassemia; $>80 \%$ for $\mathrm{Hb} \mathrm{E}$ homozygote). All subjects with elevated $\mathrm{Hb} \mathrm{A}_{2} \geq 3.5 \%$ (but lower than the expected ranges for $\mathrm{Hb} \mathrm{E}$ listed above) underwent multiplex PCR for 16 common $\beta$-globin gene mutations (listed in Table 2) as per previously published techniques [24]. The frequency of thalassemia and $\mathrm{Hb}$ variants in our migrant cohort was compared to a separate Thai community cohort that was genotyped using the same molecular approach. This larger Thai cohort $(N=1232)$ was composed of subjects aged 3 90 years (median age of 28 years; interquartile range of $20-40$ years; $69.8 \%$ female) who resided in Chonburi.

\section{Projected rates of births affected by severe thalassemia} Birth rates, or the annual number of newborns affected by severe thalassemia per 1000 births, were calculated using the Hardy-Weinberg equation similar to previously described methods $[26,27]$. Briefly, the allele frequencies of $\alpha^{0}$-thalassemia $\left(p ; \ldots\right.$ SEA and _ _ ${ }^{\text {THAI }}$ ), deletional $\alpha^{+}$-thalassemia $\left(q ;-\alpha^{3.7}\right.$ and $\left.-\alpha^{4.2}\right)$, and non-deletional $\alpha^{+}$-thalassemia $\left(r ; \alpha^{\mathrm{CS}} \alpha, \alpha^{\mathrm{PS}} \alpha, \alpha^{\mathrm{QZ}} \alpha\right.$, and $\left.\alpha^{\mathrm{WM}} \alpha\right)$ variants found in Thai, Myanmar, and Cambodian cohorts were used to calculate the expected frequencies of $\mathrm{Hb}$ Bart's hydrops fetalis $\left(p^{2}\right)$, all $\mathrm{Hb} \mathrm{H}$ disease $(2 p(q+r))$, deletional $\mathrm{Hb} \mathrm{H}$ disease $(2 p q)$, and non-deletional $\mathrm{Hb} \mathrm{H}$ disease $(2 p r)$ for each nationality. For $\beta$-thalassemia, the frequencies of homozygous $\beta$-thalassemia $\left((s+t)^{2}\right)$, all $\mathrm{Hb} \mathrm{E} / \beta$-thalassemia $(2(s+t) u), \mathrm{Hb} \mathrm{E} / \beta^{+}$-thalassemia $(2 s u)$, and $\mathrm{Hb} E / \beta^{0}$-thalassemia $(2 t u)$ were similarly calculated from the allele frequencies of $\beta^{+}$-thalassemia $(s)$, $\beta^{0}$-thalassemia $(t)$, and $\mathrm{Hb} \mathrm{E}(u)$ variants. $\mathrm{Hb} \mathrm{D}$ was excluded from this analysis. To calculate projected birth rates in each SEA population, the 2015-2020 crude birth rate from the 2019 United Nations World Population Prospects [28] and the numbers of migrant workers in Thailand from Thai Foreign Worker Administration Office [29] were used. Consanguinity was not considered in the calculations due to strong cultural norms discouraging consanguineous marriages among the Thai population [30]. 
Table 2 Common a- and $\beta$-globin mutations identified using previously described multiplex PCR-based techniques [24].

\begin{tabular}{|c|c|c|c|}
\hline No. & Globin gene type & Mutation & Mutation type \\
\hline 1 & a-globin & $-a^{3.7}$ & Single deletion \\
\hline 2 & & $-a^{4.2}$ & Single deletion \\
\hline 3 & & _ _ SEA & Double deletion \\
\hline 4 & & _ - THAl & Double deletion \\
\hline 5 & & _ - Fll & Double deletion \\
\hline 6 & & _. MED & Double deletion \\
\hline 7 & & $-(a)^{20.5}$ & Double deletion \\
\hline 8 & & _ _SIAM & Double deletion $^{a}$ \\
\hline 9 & & Initiation codon (ATG > A-G) & Non-deletion \\
\hline 10 & & Codon $30(\triangle \mathrm{GAG})$ & Non-deletion \\
\hline 11 & & Codon 59 (GGC > GAC) & Non-deletion \\
\hline 12 & & Codon 142 (Pakse; TAA > TAT) & Non-deletion \\
\hline 13 & & Codon 125 (Quang Sze; CTG > CCG) & Non-deletion \\
\hline 14 & & Codon 142 (Constant Spring; TAA > CAA) & Non-deletion \\
\hline 15 & $\beta$-globin & $n t-28(A>G)$ & $\beta^{+}$ \\
\hline 16 & & Codon 8/9 (+G) & $\beta^{0}$ \\
\hline 17 & & IVSI-5 (G >C) & $\beta^{+}$ \\
\hline 18 & & Codon 41/42 (-TTCT) & $\beta^{0}$ \\
\hline 19 & & Codon 71/72 (+A) & $\beta^{0}$ \\
\hline 20 & & Codon $17(A>T)$ & $\beta^{0}$ \\
\hline 21 & & IVSI-1 $(G>T)$ & $\beta^{0}$ \\
\hline 22 & & Codon $26 \mathrm{Hb}$ E (GAG > AAG) & $\beta^{E}$ \\
\hline 23 & & IVSII-654 (C > T) & $\beta^{+}$ \\
\hline 24 & & Codon $35(C>A)$ & $\beta^{0}$ \\
\hline 25 & & Codon $43(\mathrm{G}>\mathrm{T})$ & $\beta^{0}$ \\
\hline 26 & & Codon $26(G>T)$ & $\beta^{0}$ \\
\hline 27 & & Codon $95(+A)$ & $\beta^{0}$ \\
\hline 28 & & Codon $19(A>G)$ & $\beta^{+}$ \\
\hline 29 & & Codon $41(-C)$ & $\beta^{0}$ \\
\hline 30 & & Codon $27 / 28(+C)$ & $\beta^{0}$ \\
\hline
\end{tabular}

a The a-globin deletion - SIAM was identified using the methodology described in Riolueang et al. 2019 [25].

\section{Results}

There were 197 Thai, 119 Myanmar, and 176 Cambodian (492 total) subjects (Fig. 1 and Table 3). The median age was similar among all groups, but the Cambodian cohort had more males. Over $70 \%$ of migrants reported some proficiency in Thai. Around 60 and $27 \%$ of Thai space obtained secondary and higher education, respectively, compared to 35 and $3 \%$ of Myanmar and 30 and 1\% of Cambodians. Cambodians had the highest proportion of subjects $(\sim 27 \%)$ with no formal education. Migrants were more often married than Thai subjects but reported similar numbers of children (Table 3). Marriage to an individual with a different nationality was reported by $\sim 5 \%$ of migrants (with $8 / 11$ having a Thai spouse), while Thai subjects reported no intergroup marriages.

Myanmar subjects reported residing in Thailand for longer than Cambodians. Nevertheless, transience was surprisingly low, with the majority having never moved within Thailand. Within work sectors (Table 3), more Thai subjects reported holding white-collar jobs (e.g., managerial or sales), while migrants largely held blue-collar or informal sector jobs. Threequarters of migrant workers had previously undergone health registration, while one-quarter reported registering for the first time (i.e., were likely undocumented or "unregistered"). 
Table 3 Characteristics of the study population

\begin{tabular}{|c|c|c|c|}
\hline & $\begin{array}{l}\text { Thai } \\
(N=197)\end{array}$ & $\begin{array}{l}\text { Myanmar } \\
(N=119)\end{array}$ & $\begin{array}{l}\text { Cambodian } \\
(N=176)\end{array}$ \\
\hline Median Age (IQR), years & $32(24-40)$ & $29(24-36)$ & $30(27-37)$ \\
\hline \multicolumn{4}{|l|}{ Gender } \\
\hline Male (\%) & $71(36.0)$ & $43(36.4)$ & $100(56.8)$ \\
\hline Female (\%) & $126(64.0)$ & 75 (63.6) & $76(43.2)$ \\
\hline \multicolumn{4}{|l|}{ Languages Spoken ${ }^{\mathrm{a}}$} \\
\hline Thai (\%) & $196(99.5)$ & $73(61.3)$ & $133(76.0)$ \\
\hline Burmese (\%) & 0 & $109(91.6)$ & $7(4.1)$ \\
\hline Khmer (\%) & 0 & $2(1.7)$ & $168(97.1)$ \\
\hline English (\%) & $49(24.9)$ & 0 & $3(1.7)$ \\
\hline Mon (\%) & $1(0.5)$ & $7(5.9)$ & 0 \\
\hline Karen (\%) & 0 & $9(7.6)$ & 0 \\
\hline \multicolumn{4}{|l|}{ Highest Level of Education Achieved } \\
\hline None $(\%)$ & $2(1.0)$ & $18(15.4)$ & $48(27.4)$ \\
\hline Primary, 1-6 (\%) & $22(11.3)$ & $53(45.3)$ & $74(42.3)$ \\
\hline Secondary, 7-9 (\%) & $58(29.9)$ & $29(24.8)$ & $41(23.4)$ \\
\hline Secondary 10-12 (\%) & $58(29.9)$ & $12(10.3)$ & $11(6.3)$ \\
\hline Vocational (\%) & $24(12.4)$ & 0 & 0 \\
\hline Bachelor's degree and above (\%) & $28(14.4)$ & $3(2.6)$ & $1(0.6)$ \\
\hline \multicolumn{4}{|l|}{ Work Sector } \\
\hline Fishery (\%) & $2(1.1)$ & 0 & $2(1.2)$ \\
\hline Manufacturing (\%) & $63(34.6)$ & $40(36.0)$ & $75(43.1)$ \\
\hline Domestic (\%) & $40(22.0)$ & $37(33.3)$ & $13(7.5)$ \\
\hline Construction (\%) & $5(2.8)$ & $8(7.2)$ & $43(24.7)$ \\
\hline Other $(\%)^{b}$ & 72 (39.6) & $26(23.4)$ & $41(23.6)$ \\
\hline Median Duration in Thailand (IQR), years & NA & $6(4.25-10)$ & $5(3-6)$ \\
\hline Median Number of Times Moved (IQR) & NA & $0(0-2)$ & $0(0-2)$ \\
\hline \multicolumn{4}{|l|}{ Health Registration } \\
\hline First time (\%) & NA & $28(25.0)$ & $42(24.1)$ \\
\hline Renewal (\%) & NA & $84(75.0)$ & $132(75.9)$ \\
\hline \multicolumn{4}{|l|}{ Marital Status } \\
\hline Single $(\%)$ & $65(33.9)$ & $32(27.1)$ & $39(22.7)$ \\
\hline Married (\%) & $114(59.4)$ & $83(70.3)$ & $127(73.8)$ \\
\hline Divorced (\%) & $13(6.8)$ & $3(2.5)$ & $6(3.5)$ \\
\hline \multicolumn{4}{|l|}{ Nationality of Spouse if Married } \\
\hline Thai (\%) & $111(100)$ & $3(3.6)$ & $5(4.0)$ \\
\hline Myanmar (\%) & 0 & $75(93.8)$ & $2(1.7)$ \\
\hline Cambodian (\%) & 0 & $1(1.3)$ & $113(94.2)$ \\
\hline Median Number of Children (IQR) & $2(1-2)$ & $1(0-2)$ & $2(1-2)$ \\
\hline
\end{tabular}

IQR Inter-quartile range, NA Not applicable

${ }^{a}$ Ethnic minority languages were reported by the Myanmar cohort, including Mon (5.9\%), Karen (7.6\%), and Chinese (0.8\%), but not by the Thai or Cambodian cohorts

b The large majority of jobs in the "Other" category were reported to be sales-related, with job descriptions ranging from company salesmen to street vendors. Other job sectors included business, civil, and farming. Some subjects reported being students or freelance/self-employed 
Healthcare utilization is lower among migrants

Most subjects preferred to first seek care from a doctor or medical facility. Drug stores were the next most preferred contact, while few reported seeking care from traditional healers (Table 4). Thai and Cambodian subjects relied heavily on public health insurance. Migrants generally used cash more often than Thai subjects to pay for health care $(\sim 36 \%$ vs. $11 \%)$. Thai subjects had a

Table 4 Comparison of thalassemia-related health literacy and health behaviors among Thai, Myanmar, and Cambodian subjects

\begin{tabular}{|c|c|c|c|}
\hline & $\begin{array}{l}\text { Thai } \\
(N=197)\end{array}$ & $\begin{array}{l}\text { Myanmar } \\
(N=119)\end{array}$ & $\begin{array}{l}\text { Cambodian } \\
(N=176)\end{array}$ \\
\hline \multicolumn{4}{|l|}{ Health-seeking Behaviors } \\
\hline \multicolumn{4}{|l|}{ First Point of Contact When Sick } \\
\hline Drug store (\%) & $71(37.6)$ & $47(40.2)$ & $77(44.8)$ \\
\hline Doctor (\%) & $115(60.9)$ & $65(55.6)$ & $88(51.2)$ \\
\hline Traditional healer (\%) & $1(0.5)$ & $3(2.6)$ & $3(1.7)$ \\
\hline Other $(\%)^{a}$ & $2(1.1)$ & $2(1.7)$ & $4(2.3)$ \\
\hline Median Number of Doctor Visits in 1 year (IQR) & $1(0-3)$ & $0(0-1)$ & $0(0-2)$ \\
\hline \multicolumn{4}{|l|}{ Method of Payment for Healthcare } \\
\hline Public Insurance (\%) & $82(44.1)$ & $37(31.4)$ & $80(46.2)$ \\
\hline Employer Insurance (\%) & $52(28.0)$ & $29(24.6)$ & $30(17.3)$ \\
\hline Private Insurance (\%) & $18(9.7)$ & $1(0.9)$ & $1(0.6)$ \\
\hline Cash (\%) & $19(10.2)$ & $49(41.5)$ & $53(30.6)$ \\
\hline Other $(\%)^{b}$ & $15(8.1)$ & $2(1.7)$ & $9(5.2)$ \\
\hline Want to test self for thalassemia $(\%)^{c}$ & $25(62.5)$ & $67(61.5)$ & $147(86.5)$ \\
\hline Want to test baby for thalassemia $(\%)^{c}$ & $29(72.5)$ & $77(70.6)$ & $145(86.8)$ \\
\hline Want to test partner for thalassemia $(\%)^{c}$ & $29(78.4)$ & $81(74.3)$ & $150(88.8)$ \\
\hline \multicolumn{4}{|l|}{ Best Method for Thalassemia Education } \\
\hline Consultation with doctor (\%) & $26(68.4)$ & $93(86.9)$ & $144(84.2)$ \\
\hline Brochure (\%) & $1(2.6)$ & $8(7.5)$ & $10(5.9)$ \\
\hline Employer workshop (\%) & $1(2.6)$ & $1(0.9)$ & $2(1.2)$ \\
\hline Government workshop (\%) & $5(13.2)$ & $2(1.9)$ & $5(2.9)$ \\
\hline Other $(\%)^{d}$ & $5(13.2)$ & $3(2.8)$ & $10(5.9)$ \\
\hline \multicolumn{4}{|l|}{ Thalassemia-related Health Literacy } \\
\hline Aware of Anemia (\%) & $151(80.3)$ & $23(20.0)$ & $24(13.7)$ \\
\hline Aware of Thalassemia (\%) & $156(79.6)$ & $8(6.8)$ & $4(2.3)$ \\
\hline \multicolumn{4}{|l|}{ Personal History of: } \\
\hline Anemia (\%) & $31(16.0)$ & $7(6.0)$ & $7(4.1)$ \\
\hline Thalassemia (\%) & $12(6.2)$ & 0 & $3(1.7)$ \\
\hline Transfusion (\%) & $13(6.7)$ & $1(0.9)$ & $10(5.8)$ \\
\hline Miscarriage (\%) & $15(7.9)$ & $8(6.9)$ & $11(6.4)$ \\
\hline \multicolumn{4}{|l|}{ Family History of: } \\
\hline Anemia (\%) & $34(17.4)$ & $4(3.5)$ & $9(5.2)$ \\
\hline Thalassemia (\%) & $11(5.7)$ & $1(0.9)$ & $1(0.6)$ \\
\hline Transfusion (\%) & $15(7.8)$ & $2(1.7)$ & $6(3.5)$ \\
\hline Miscarriage (\%) & $17(8.9)$ & $5(4.4)$ & $8(4.6)$ \\
\hline
\end{tabular}

IQR Inter-quartile range

a Other preferred sources of medical care included on-site clinics provided by the employer in workplaces such as factories, or multiple sources of medical care were selected

${ }^{\mathrm{b}}$ Other methods of payment include civil insurance and the selection of multiple sources of medical care

' Subjects unaware of thalassemia were asked whether they would want to test themselves, their babies, or their partners for an inherited disease, such as thalassemia

${ }^{d}$ Other preferred methods of education included mass media (television, internet), word of mouth (friends, employers, spouse), or multiple sources 
higher median number of doctor visits within the past 1 year compared to migrants (Table 4). Unregistered status was associated with shorter length of residence (median 4.0 years, vs. 5.1 years for registered migrants).

\section{Migrants have very low thalassemia awareness but show interest in thalassemia screening}

Most Thai subjects were aware of anemia and thalassemia (both $\sim 80 \%$ ). In contrast, a minority of Myanmar and Cambodian migrants were aware of anemia (20 and $13.7 \%$ ), and few were aware of thalassemia (6.8 and $2.3 \%)$. Thai subjects also reported more personal and family history of anemia, thalassemia, and blood transfusion compared to migrants (Table 4).

Subjects without awareness of thalassemia were briefly informed about thalassemia and asked if they were interested in thalassemia screening. Most expressed interest, with Cambodians showing greatest interest. All groups preferred to receive thalassemia education through consultations with a doctor, with migrants showing a stronger preference (Table 4).

\section{Factors associated with thalassemia awareness}

Subgroup analysis of factors predicting thalassemia awareness in migrants revealed an association with longer residence duration in Thailand (median 13.1 vs. 5.0 years; $\mathrm{Z}=3.82, p=0.0002$ ). Within the Thai subgroup, females had 2.12 times higher odds (95\% CI 1.05-4.29; $p=0.03$ ) of being aware of thalassemia compared to males, and those with secondary education had 2.69 times higher odds (95\% CI 1.08-6.71, p=0.03) than those less educated. Among both Thai and migrant subjects, awareness of anemia strongly predicted thalassemia awareness $(\mathrm{OR}=11.07$ [95\% CI 4.82-25.44, $p<0.0001$ ] and 18.87 [95\% CI 4.89, 72.84, p $<0.0001$ ], respectively).

\section{Comparison of knowledge, attitudes, and practices of migrant vs. Thai subjects}

Thalassemia knowledge was lower for migrants compared to Thai subjects (median knowledge score of 7 (IQR 6-8) vs. 8 (IQR 7-10), $\mathrm{Z}=-3.10, p=0.002$, Table 5). Only $27.3 \%$ of migrants knew that thalassemia was common in Asia, vs. $72.3 \%$ of Thai subjects. Compared to $54.2 \%$ of Thai subjects, $90.9 \%$ of migrants thought a thalassemia carrier could develop thalassemia major. However, both groups held key misconceptions: $32.9 \%$ of Thai and $45.4 \%$ of migrant subjects believed that thalassemia was an infectious disease, and 39.3 and $54.5 \%$, respectively, believed that thalassemia was curable with a pill rather than a chronic disease. Understanding of carrier status was poor; most Thai and migrant subjects believed that non-carrier couples could give birth to a child with thalassemia and that thalassemia carriers require blood transfusions. Subjects without secondary education had lower knowledge levels than those with secondary education (median score of 6 (IQR 6-9) vs. 8 (IQR 8-10), $\mathrm{Z}=3.30, p=0.001)$. Age, gender, and health-seeking behaviors did not correlate with knowledge scores.

Attitude scores were considered a proxy for subjects' attitudes towards thalassemia prevention and control, with a score of 5 indicating strong support and 1 indicating strong opposition. The median attitude score was 3.4 (IQR 3.2-3.8) for Thai subjects and 3.7 (IQR 3.33.9) for migrants, suggesting that subjects leaned towards supporting thalassemia prevention overall. Examining individual questions, Thai and migrant subjects agreed that thalassemia should be prevented, that having a child with thalassemia was more of a burden than a blessing, and that they preferred to know whether their pregnancy was affected by thalassemia and would test themselves and their partners (Table 5). Paradoxically, migrants expressed a stronger desire to know whether a pregnancy was affected by thalassemia (Questions 16 and 20) but held more negative attitudes toward actual termination of pregnancy (Questions 23-26, Table 5). No correlation between knowledge and attitude scores was found. Cronbach's $\alpha$ for internal reliability of the survey tool was 0.66 for knowledge questions and 0.67 for attitude questions.

Finally, Thai subjects and their partners reported having been tested for thalassemia more often than migrants (Table 5). Of those tested, around two-thirds reported undergoing prenatal diagnosis (PND), leading to a diagnosis of severe thalassemia in one migrant pregnancy and four Thai pregnancies; the decision for termination of pregnancy was not captured. Most subjects in both groups planned to have more children in the future (Table 5).

\section{Thalassemia is prevalent in migrants, and screening is feasible and acceptable}

Of the 300 migrants surveyed, 286 subjects (95.3\%) underwent phlebotomy and had residual blood samples available for thalassemia testing, demonstrating the feasibility of obtaining blood samples for thalassemia testing during the health registration process. Of the 286 subjects, 277 (96.9\%) consented to thalassemia testing, suggesting that thalassemia testing is acceptable to migrants. We identified at least one $\alpha$ - or $\beta$-globin mutation in $53.4 \%(148 / 277)$ of migrants, compared to $43.8 \%$ $(540 / 1232)$ of Thai subjects in a separate cohort (Table 6).

The most common variants identified were $-\alpha^{3.7}$ and $\mathrm{Hb}$ E. The Myanmar and Cambodian cohorts had a higher frequency of deletional $\alpha^{+}$-thalassemia alleles ( 0.186 and 0.183 , respectively) compared to the Thai cohort (0.088). Hb E allele frequency was highest amongst 
Table 5 Individual question responses and cumulative knowledge and attitude scores from the KAP survey

\begin{tabular}{|c|c|c|}
\hline & $\begin{array}{l}\text { Thai } \\
(N=155)\end{array}$ & $\begin{array}{l}\text { Migrant } \\
(N=11)\end{array}$ \\
\hline \multicolumn{3}{|l|}{ Knowledge Questions (\% Correct) } \\
\hline 1. Thalassemia is blood disease. & $94.8 \%$ & $72.7 \%$ \\
\hline 2. Thalassemia is cause of anemia. & $87.7 \%$ & $81.8 \%$ \\
\hline 3. Thalassemia is rare in Asia. & $72.3 \%$ & $27.3 \%$ \\
\hline 4. Thalassemia is infectious disease. & $67.1 \%$ & $54.6 \%$ \\
\hline 5. Thalassemia is inherited disease. & $91.0 \%$ & $72.7 \%$ \\
\hline 6. Normal parents can have affected child. & $25.8 \%$ & $9.1 \%$ \\
\hline 7. Carrier parents at risk for affected pregnancy. & $70.3 \%$ & $63.6 \%$ \\
\hline 8. Blood test can be done. & $97.4 \%$ & $100.0 \%$ \\
\hline 9. Thalassemia carrier requires transfusions. & $42.6 \%$ & $36.4 \%$ \\
\hline 10. Thalassemia major requires transfusions. & $86.5 \%$ & $90.9 \%$ \\
\hline 11. A carrier can develop thalassemia major. & $45.8 \%$ & $9.1 \%$ \\
\hline 12. Can cure thalassemia with pill. & $60.7 \%$ & $45.5 \%$ \\
\hline Median Knowledge Score $(I Q R)^{\text {a }}$ & $8(7-10)$ & $7(6-8)$ \\
\hline \multicolumn{3}{|l|}{ Attitude Questions (Median, IQR) } \\
\hline 13. Thalassemia should be prevented. & $4(4-5)$ & $5(5-5)$ \\
\hline 14. Child with thalassemia is burden. & $3(2-4)$ & $4(2-5)$ \\
\hline 15. Child with thalassemia is blessing. & $1(1-2)$ & $1(1-2)$ \\
\hline 16. Want to know if having baby affected. & $4(4-5)$ & $5(4-5)$ \\
\hline 17. Would get tested during pregnancy. & $5(4-5)$ & $5(5-5)$ \\
\hline 18. Want partner tested during pregnancy. & $5(4-5)$ & $5(3-5)$ \\
\hline 19. Have children with partner if both carriers. & $3(2-4)$ & $1(1-3)$ \\
\hline 20. Would not want to know if baby affected. & $2(1-4)$ & $1(1-1)$ \\
\hline 21. Testing during pregnancy not useful. & $3(1-4)$ & $1(1-5)$ \\
\hline 22. Not have children with partner if both carriers. & $3(2-5)$ & $1(1-5)$ \\
\hline 23. Would end pregnancy for thalassemia. & $3(2-4)$ & $2(1-5)$ \\
\hline 24. Disagree with ending pregnancy. & $4(3-4)$ & $5(4-5)$ \\
\hline 25. Would not prevent birth of affected baby. & $3(3-4)$ & $5(1-5)$ \\
\hline 26. Better to end pregnancy than let child suffer. & $4(3-4)$ & $3(1-5)$ \\
\hline Median Attitude Score $(I Q R)^{b}$ & $3.4(3.2-3.8)$ & $3.7(3.3-3.9)$ \\
\hline \multicolumn{3}{|l|}{ Practice Questions (N, \%) } \\
\hline 27. Subject tested for thalassemia. & $72(46.8)$ & $3(27.3)$ \\
\hline 28. Partner tested for thalassemia. & $59(38.3)$ & $1(9.1)$ \\
\hline 29. Had prenatal diagnosis (PND). & $53(68.0)$ & $2(66.7)$ \\
\hline 30. PND showed affected baby. & $4(7.6)$ & $1(50.0)$ \\
\hline 31. Plan to have more children. & $94(62.7)$ & $8(72.7)$ \\
\hline
\end{tabular}

${ }^{a}$ The Knowledge Score was defined as the number of correctly answered knowledge questions (out of 12 possible points). The median Knowledge Score was higher in Thai vs migrant subjects $(p=0.002)$

$\mathrm{b}$ The Attitude Score was defined as the mean value of 14 attitude questions scored according to the Likert scale $($ Strongly agree $=5$ points, Agree $=4$, Unsure $=3$, Disagree $=2$, and Strongly disagree $=1$ ), with inverse questions scored in reverse. There was no statistical difference between median Attitude Scores among Thai vs migrant subjects $(p=0.21)$

Cambodians (0.192), and $\beta$-thalassemia allele frequency highest amongst Myanmar (0.025). Non-deletional $\alpha$-globin variants $(\mathrm{Hb}$ Constant Spring, $\mathrm{Hb}$ Pakse, and $\mathrm{Hb}$ Quang Sze) and deletional $\alpha^{0}$-thalassemia variants (- _ ${ }^{\text {SEA }}$ and - ${ }^{\text {THAI }}$ ) were more frequent in the Thai cohort. Around $15 \%$ of Cambodians were double heterozygous carriers of $\alpha$ - and $\beta$-globin variants due to high frequencies of $\mathrm{Hb} \mathrm{E}$ and $-\alpha^{3.7}$, compared to $4-5 \%$ of the Thai and 
Table 6 Allele frequencies of the most common hemoglobin variants identified in Thai vs. migrant cohorts

\begin{tabular}{|c|c|c|c|c|}
\hline & & Migrant & & \\
\hline & $\begin{array}{l}\text { Thai } \\
(N=1232)\end{array}$ & $\begin{array}{l}\text { Myanmar } \\
(N=121)\end{array}$ & $\begin{array}{l}\text { Cambodian } \\
(N=156)\end{array}$ & $\begin{array}{l}\text { Combined } \\
(N=277)\end{array}$ \\
\hline Deletional $\mathbf{a}^{+}$-thalassemia & 0.088 & 0.186 & 0.183 & 0.184 \\
\hline$a^{3.7}$ & 0.080 & 0.182 & 0.179 & 0.181 \\
\hline$-a^{4.2}$ & 0.008 & 0.004 & 0.003 & 0.004 \\
\hline Deletional $a^{0}$ - thalassemia & 0.022 & 0.004 & 0.013 & 0.009 \\
\hline - SEA & 0.022 & 0.004 & 0.010 & 0.007 \\
\hline _ _ THAl & 0 & 0 & 0.003 & 0.002 \\
\hline Non-deletional $\mathbf{a}^{+}$- thalassemia & 0.026 & 0 & 0.003 & 0.002 \\
\hline $\mathrm{Hb}$ Constant Spring & 0.024 & 0 & 0 & 0 \\
\hline Hb Pakse & 0.001 & 0 & 0.003 & 0.002 \\
\hline $\mathrm{Hb} \mathrm{E}$ & 0.127 & 0.058 & 0.192 & 0.134 \\
\hline$\beta$-thalassemia $\left(\beta^{0}\right.$ or $\left.\beta^{+}\right)$ & 0.007 & 0.025 & 0.003 & 0.013 \\
\hline$\beta^{\mid \mathrm{ISS}-1}$ & 0.001 & 0.012 & 0.003 & 0.007 \\
\hline$\beta^{\mathrm{CD} 17}$ & 0.002 & 0 & 0 & 0 \\
\hline$\beta^{C D 71 / 72}$ & 0.0004 & 0.004 & 0 & 0.002 \\
\hline$\beta^{C D 41 / 42}$ & 0.001 & 0 & 0 & 0 \\
\hline
\end{tabular}

Myanmar cohorts (Table 7). Severe thalassemia disease syndromes (11, $\mathrm{Hb} \mathrm{H}$ disease; $1, \mathrm{Hb} \mathrm{E} / \beta$-thalassemia) were only identified in the Thai cohort. Rare $\alpha$ - and $\beta$-globin variants were found in Thai ( $\mathrm{Hb}$ Westmead, $\mathrm{Hb}$ Quang Sze, and $\mathrm{Hb} \mathrm{D}$ ) and migrant (Hb Showa-Yakushiji) cohorts (Table 7).

\section{Higher rate of births with severe thalassemia among migrant populations}

Based on prevalence estimates from this study, the projected rate of births affected by all thalassemia diseases is $11.193 / 1000$ births/year in migrants and 9.167/1000 births/year in the Thai population. Projected birth rates are highest for $\mathrm{Hb}$ Bart's hydrops fetalis and $\mathrm{Hb} E / \beta$ thalassemia in the Thai population and for homozygous $\beta$-thalassemia in the Myanmar migrant population (Table 8). Projected $\mathrm{Hb} \mathrm{H}$ disease birth rates are similar in Thai and Cambodian migrant populations but lower in Myanmar migrants (4.885 and 4.759 vs. $1.525 / 1000$ births/year, respectively). The projected number of newborns in the Thai population with $\mathrm{Hb}$ Bart's hydrops fetalis and $\mathrm{Hb} \mathrm{H}$ disease, adjusted for annual birth rate, is comparable to previous estimates [27], but the number of Thai newborns affected by $\beta$-thalassemia syndromes is higher than prior estimates [31] (Table 8).

\section{Discussion}

This is the first study characterizing thalassemia knowledge, attitudes, and health-related behaviors of migrant populations in Thailand and one of few studies examining beliefs and perceptions surrounding thalassemia in
SEA. Through comprehensive thalassemia testing, we identified a higher proportion of thalassemia carriers and higher allele frequencies of some globin variants in a migrant cohort compared to a Thai cohort. Furthermore, using prevalence estimates, we found a higher projected rate of births affected by severe thalassemia in the migrant cohort compared to the Thai cohort, highlighting the significant disease burden in migrants that needs to be addressed.

We hypothesized existence of a significant gap in thalassemia awareness between Thai and migrant subjects; indeed, only $4 \%$ of migrants vs. $80 \%$ of Thai subjects had heard of thalassemia. Thalassemia awareness was associated with female gender and achieving secondary education in the Thai cohort. Our migrant cohort, on average, was more male and less educated. Consistent with migrants' length of residence in Thailand being a proxy for linguistic integration and exposure to mass media, migrants aware of thalassemia had resided in Thailand longer. Additional potential factors leading to increased awareness in long-term migrant residents include increased likelihood of interaction with the healthcare system and larger social networks, in which knowledge of thalassemia may spread by word of mouth.

A study of thalassemia awareness among Italians vs. Italian-Americans also found a large knowledge gap ( $85 \%$ vs. $19 \%$ ), attributed to exposure to thalassemia education and screening in Italy and the lack of such programs in the United States [23]. A similar disparity in exposure may underlie our findings, as Thailand's thalassemia prevention and control programs only offer 
Table 7 a- and $\beta$-globin genotypes identified in Thai and migrant cohorts in Chonburi, Thailand

\begin{tabular}{|c|c|c|c|c|c|c|c|c|c|}
\hline \multirow[t]{3}{*}{ Disease Category } & \multirow[t]{3}{*}{ Genotype } & & & \multicolumn{6}{|c|}{ Migrants } \\
\hline & & \multicolumn{2}{|c|}{ Thai $(N=1232)$} & \multicolumn{2}{|c|}{ Myanmar $(N=121)$} & \multicolumn{2}{|c|}{ Cambodian $(N=156)$} & \multicolumn{2}{|c|}{ Combined $(N=277)$} \\
\hline & & $\mathrm{N}$ & $\%$ & $\mathrm{~N}$ & $\%$ & $\mathrm{~N}$ & $\%$ & $\mathrm{~N}$ & $\%$ \\
\hline \multirow[t]{10}{*}{ Carriers of a-globin variant } & $-a^{3.7} / a a$ & 126 & 10.2 & 34 & 28.1 & 30 & 19.2 & 64 & 23.1 \\
\hline & $-a^{4.2} / a a$ & 13 & 1.1 & 1 & 0.8 & 0 & 0 & 1 & 0.4 \\
\hline & $-a^{3.7} /-a^{3.7}$ & 4 & 0.3 & 2 & 1.7 & 1 & 0.6 & 3 & 1.1 \\
\hline & $-a^{3.7} /-a^{4.2}$ & 1 & 0.1 & 0 & 0 & 1 & 0.6 & 1 & 0.4 \\
\hline & $-a^{3.7} / a^{C S} a$ & 8 & 0.6 & 0 & 0 & 0 & 0 & 0 & 0 \\
\hline & . SEA $/ a a$ & 34 & 2.8 & 1 & 0.8 & 2 & 1.3 & 3 & 1.1 \\
\hline & $a^{C S} a / a a$ & 35 & 2.8 & 0 & 0 & 0 & 0 & 0 & 0 \\
\hline & $a^{p s} a / a a$ & 1 & 0.1 & 0 & 0 & 0 & 0 & 0 & 0 \\
\hline & $a^{Q Z} a / a a$ & 1 & 0.1 & 0 & 0 & 0 & 0 & 0 & 0 \\
\hline & Total & 223 & 18.1 & 38 & 31.4 & 34 & 21.8 & 72 & 26.0 \\
\hline \multirow[t]{11}{*}{ Carriers of $\beta$-globin variant } & $\beta^{\mathrm{E}} / \beta$ & 186 & 15.1 & 10 & 8.3 & 29 & 18.6 & 39 & 14.1 \\
\hline & $\beta^{D} / \beta$ & 3 & 0.2 & 0 & 0 & 0 & 0 & 0 & 0 \\
\hline & $\beta^{\mid V S I-1} / \beta$ & 1 & 0.1 & 1 & 0.8 & 1 & 0.6 & 2 & 0.7 \\
\hline & $\beta^{\mid V 5 I I-654} / \beta$ & 1 & 0.1 & 0 & 0 & 0 & 0 & 0 & 0 \\
\hline & $\beta^{\mathrm{CD} 17} / \beta$ & 5 & 0.4 & 0 & 0 & 0 & 0 & 0 & 0 \\
\hline & $\beta^{\mathrm{CD} 71 / 72 / \beta}$ & 1 & 0.1 & 1 & 0.8 & 0 & 0 & 1 & 0.4 \\
\hline & $\beta^{\mathrm{CD} 41 / 42 / \beta}$ & 1 & 0.1 & 0 & 0 & 0 & 0 & 0 & 0 \\
\hline & $\beta^{\mathrm{CD} 27 / 28} / \beta$ & 1 & 0.1 & 0 & 0 & 0 & 0 & 0 & 0 \\
\hline & $\beta^{-28} / \beta$ & 1 & 0.1 & 0 & 0 & 0 & 0 & 0 & 0 \\
\hline & $\beta^{-3.48} / \beta$ & 2 & 0.2 & 1 & 0.8 & 0 & 0 & 1 & 0.4 \\
\hline & Total & 202 & 16.4 & 13 & 10.7 & 30 & 19.2 & 43 & 15.5 \\
\hline \multirow[t]{15}{*}{ Double heterozygous carriers } & $-a^{3.7} / a a+\beta^{E} / \beta$ & 28 & 2.3 & 2 & 1.7 & 18 & 11.5 & 20 & 7.2 \\
\hline & $-a^{4.2} / a a+\beta^{E} / \beta$ & 6 & 0.5 & 0 & 0 & 0 & 0 & 0 & 0 \\
\hline & $-a^{3.7} /-a^{3.7}+\beta^{E} / \beta$ & 5 & 0.4 & 0 & 0 & 2 & 1.3 & 2 & 0.7 \\
\hline & $-{ }^{\mathrm{SEA}} / \alpha a+\beta^{\mathrm{E}} / \beta$ & 8 & 0.6 & 0 & 0 & 1 & 0.6 & 1 & 0.4 \\
\hline & $\ldots{ }^{\text {THAl }} / a \alpha+\beta^{E} / \beta$ & 0 & 0 & 0 & 0 & 1 & 0.6 & 1 & 0.4 \\
\hline & $a^{C S} a / a a+\beta^{E} / \beta$ & 5 & 0.4 & 0 & 0 & 0 & 0 & 0 & 0 \\
\hline & $a^{P S} a / a a+\beta^{E} / \beta$ & 0 & 0 & 0 & 0 & 1 & 0.6 & 1 & 0.4 \\
\hline & $-a^{3.7} / a a+\beta^{D} / \beta$ & 1 & 0.1 & 0 & 0 & 0 & 0 & 0 & 0 \\
\hline & $-a^{3.7} / a a+\beta^{C D 41 / 42} / \beta$ & 1 & 0.1 & 0 & 0 & 0 & 0 & 0 & 0 \\
\hline & $-a^{3.7} / \alpha a+\beta^{C D 35} / \beta$ & 1 & 0.1 & 0 & 0 & 0 & 0 & 0 & 0 \\
\hline & $-a^{3.7} / a a+\beta^{-28} / \beta$ & 1 & 0.1 & 0 & 0 & 0 & 0 & 0 & 0 \\
\hline & $-a^{3.7} / a a+\beta^{\mid V S L-1} / \beta$ & 0 & 0 & 2 & 0.8 & 0 & 0 & 2 & 0.7 \\
\hline & $-a^{3.7} / a a+\beta^{C D 110} / \beta^{a}$ & 0 & 0 & 1 & 0.8 & 0 & 0 & 1 & 0.4 \\
\hline & $a^{C S} a / a a+\beta^{\mid V S I-1} / \beta$ & 1 & 0.1 & 0 & 0 & 0 & 0 & 0 & 0 \\
\hline & Total & 57 & 4.6 & 5 & 4.1 & 23 & 14.7 & 28 & 10.1 \\
\hline \multirow[t]{5}{*}{ Homozygous Hb E (with/without a-thalassemia) } & $\beta^{E} / \beta^{E}$ & 25 & 2.0 & 0 & 0 & 3 & 0.2 & 3 & 1.1 \\
\hline & $-a^{3.7} / a a+\beta^{E} / \beta^{E}$ & 4 & 0.3 & 1 & 0.1 & 1 & 0.1 & 2 & 0.7 \\
\hline & $-a^{3.7} /-a^{3.7}+\beta^{E} / \beta^{E}$ & 1 & 0.1 & 0 & 0 & 0 & 0 & 0 & 0 \\
\hline & $a^{C S} a / a a+\beta^{E} / \beta^{E}$ & 3 & 0.2 & 0 & 0 & 0 & 0 & 0 & 0 \\
\hline & Total & 33 & 2.7 & 1 & 0.8 & 4 & 2.6 & 5 & 1.8 \\
\hline \multirow[t]{5}{*}{ Hb H disease (with/without a-thalassemia) } & - SEA $_{-}-a^{3.7}$ & 6 & 0.5 & 0 & 0 & 0 & 0 & 0 & 0 \\
\hline & $\ldots \mathrm{SEA} / \mathrm{a}^{\mathrm{CS}} \mathrm{a}$ & 3 & 0.2 & 0 & 0 & 0 & 0 & 0 & 0 \\
\hline & $\ldots$ SEA $/ \alpha^{C S} \alpha+\beta^{E} / \beta$ & 1 & 0.1 & 0 & 0 & 0 & 0 & 0 & 0 \\
\hline & $\ldots$ SEA $/ a^{W M} a+\beta^{E} / \beta$ & 1 & 0.1 & 0 & 0 & 0 & 0 & 0 & 0 \\
\hline & Total & 11 & 0.9 & 0 & 0 & 0 & 0 & 0 & 0 \\
\hline
\end{tabular}


Table 7 a- and $\beta$-globin genotypes identified in Thai and migrant cohorts in Chonburi, Thailand (Continued)

\begin{tabular}{|c|c|c|c|c|c|c|c|c|c|}
\hline \multirow[t]{3}{*}{ Disease Category } & \multirow[t]{3}{*}{ Genotype } & & & \multicolumn{6}{|c|}{ Migrants } \\
\hline & & \multicolumn{2}{|c|}{ Thai $(N=1232)$} & \multicolumn{2}{|c|}{ Myanmar $(N=121)$} & \multicolumn{2}{|c|}{ Cambodian $(N=156)$} & \multicolumn{2}{|c|}{ Combined $(N=277)$} \\
\hline & & $\mathrm{N}$ & $\%$ & $\mathrm{~N}$ & $\%$ & $\mathrm{~N}$ & $\%$ & $\mathrm{~N}$ & $\%$ \\
\hline \multirow[t]{2}{*}{ Compound heterozygous $\beta$-thalassemia } & $\beta^{\mathrm{CD} 41 / 42} / \beta^{\mathrm{E}}$ & 1 & 0.1 & 0 & 0 & 0 & 0 & 0 & 0 \\
\hline & Total & 1 & 0.1 & 0 & 0 & 0 & 0 & 0 & 0 \\
\hline \multirow[t]{5}{*}{ Other a-thalassemia diseases } & $a^{C S} a / a^{C S} a$ & 1 & 0.1 & 0 & 0 & 0 & 0 & 0 & 0 \\
\hline & $a^{C S} a / a^{P S} a+\beta^{E} / \beta$ & 1 & 0.1 & 0 & 0 & 0 & 0 & 0 & 0 \\
\hline & a triplication & 5 & 0.4 & NT & NT & NT & NT & NT & NT \\
\hline & a triplication $+\beta^{\mathrm{E}} / \beta$ & 6 & 0.5 & NT & NT & NT & NT & NT & NT \\
\hline & Total & 13 & 1.1 & 0 & 0 & 0 & 0 & 0 & 0 \\
\hline Any thalassemia carrier & Total & 540 & 43.8 & 57 & 47.1 & 91 & 58.3 & 148 & 53.4 \\
\hline
\end{tabular}

NT Not tested, CS Constant Spring, PS Pakse, QZ Quang Sze, WM Westmead

${ }^{a} \beta^{\mathrm{CD} 110}$ is also known as $\mathrm{Hb}$ Showa-Yakushiji

education, outreach, and free prenatal screening to Thai citizens and are not accessible to migrants. Education is an effective approach to lowering the burden of thalassemia [23, 32], and as such, bolstering education efforts in migrant communities could be a rational initial approach to addressing this awareness gap. However, educational efforts may be hindered by sociocultural barriers.

Education level and literacy were lower for migrant than Thai subjects in this study. Awareness of thalassemia was correlated with attainment of secondary education, as well as with awareness of hematological disorders in general, a measure of health literacy. Migrants also demonstrated a lower understanding of the genetic inheritance of thalassemia. A study in Yangon, Myanmar, found that even among mothers of children receiving regular care for thalassemia, only $18-28 \%$ had an understanding of genetic inheritance [19]. Therefore, effective thalassemia programs for migrant populations should also emphasize genetic education and counseling. In addition, Thai females were more aware of thalassemia than males, possibly related to Thailand's prenatal approach to thalassemia prevention, providing women with more exposure through antenatal care clinics. For male migrant workers, alternative settings for screening and education should be explored.

Our study also highlights the significant structural barriers faced by migrant populations. One-quarter of our

Table 8 Comparison of estimates of affected newborns with thalassemia disease for Thai populations and migrant workers

\begin{tabular}{|c|c|c|c|c|c|}
\hline & $\begin{array}{l}\text { Thai } \\
\text { (Current study) }\end{array}$ & $\begin{array}{l}\text { Thai (Hockham } \\
\text { et al., 2019) [27] }\end{array}$ & $\begin{array}{l}\text { Thai (Fucharoen } \\
\text { et al., 2014) [31] }\end{array}$ & $\begin{array}{l}\text { Myanmar } \\
\text { (Current study) }\end{array}$ & $\begin{array}{l}\text { Cambodian } \\
\text { (Current study) }\end{array}$ \\
\hline \multicolumn{6}{|l|}{ Hb Bart's hydrops fetalis } \\
\hline - Affected newborns (cases/1000 birth/year) & 0.462 & N/A & N/A & 0.017 & 0.164 \\
\hline - Affected newborns in Thailand ${ }^{\mathrm{a}}$ (cases/year) & 335 & 423 (Cl: 184-761) & 833 & $<1(0.18)$ & $<1(0.23)$ \\
\hline \multicolumn{6}{|l|}{$\mathrm{Hb} H$ disease (all) } \\
\hline - Affected newborns (cases/1000 birth/year) & 4.885 & N/A & N/A & 1.525 & 4.759 \\
\hline - Affected newborns in Thailand ${ }^{a}$ (cases/year) & 3540 & 3172 & 5600 & 16 & 7 \\
\hline - Deletional Hb H disease (cases/year) & 2742 & 2674 (Cl:1296-4491) & N/A & 16 & 7 \\
\hline - Non-deletional Hb H disease (cases/year) & 798 & $498(\mathrm{Cl}: 237-947)$ & N/A & 0 & $0(0.1)$ \\
\hline \multicolumn{6}{|l|}{ Homozygous $\beta$-thalassemia } \\
\hline - Affected newborns (cases/1000 birth/year) & 0.202 & N/A & N/A & 0.615 & 0.010 \\
\hline - Affected newborns in Thailand ${ }^{a}$ (cases/year) & 146 & N/A & 207 & 7 & $<1(0.01)$ \\
\hline \multicolumn{6}{|l|}{$\mathrm{Hb} \mathrm{E} / \beta$-thalassemia } \\
\hline - Affected newborns (cases/1000 birth/year) & 3.618 & N/A & N/A & 2.872 & 1.231 \\
\hline - Affected newborns in Thailand ${ }^{a}$ (cases/year) & 2622 & N/A & 3213 & 31 & 2 \\
\hline - $\mathrm{Hb} E / \beta^{+}$-thalassemia (cases/year) & 1126 & N/A & N/A & 5 & 0 \\
\hline$\cdot \mathrm{Hb}$ E/ $\beta^{0}$-thalassemia (cases/year) & 1496 & N/A & N/A & 26 & 2 \\
\hline
\end{tabular}

NA Not available, Cl 95\% confidence interval

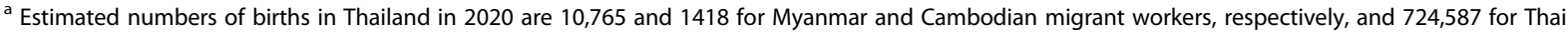
population [28] 
migrant cohort was unregistered, i.e., without legal documentation or access to public health insurance, potentially influencing their health seeking behaviors. Migrants were more likely to pay for healthcare with cash and less likely to have multiple types of insurance compared to Thai subjects, likely leading to higher outof-pocket costs and lower healthcare utilization. Cost of thalassemia testing was a commonly raised concern among migrants, underscoring the need for a government-sponsored program for thalassemia prevention for migrants, similar to that for Thai citizens.

Other structural barriers related to employment, transportation, and lack of interpreters for migrants were frequently encountered during this study. Subjects undergoing thalassemia testing were offered a return of results through either domestic mail or in-person pickup at $\mathrm{LCH}$, as well as free thalassemia genetic counseling at $\mathrm{LCH}$. The vast majority of migrants expressed interest in learning their thalassemia carrier status and requested the return of results but declined to return for counseling due to concerns over missing work or finding transportation. Despite having translated study documents to Thai, Burmese, and Khmer, we faced tremendous language barriers due to poor literacy among migrants, as well as the limited availability and quality of interpreters, which likely impacted subjects' comprehension of more complex or inverted survey items (e.g., Questions 19 and 22, Table 5). Addressing structural barriers hindering the delivery of thalassemia prevention and care to migrants may require concurrent changes in immigration and employment policies, particularly as half of the migrant population in Thailand may be unregistered [33].

Additionally, the KAP survey revealed important misconceptions and beliefs that may reduce the acceptance of thalassemia screening. A large percentage of migrants believed thalassemia to be an infectious disease; correction of this and other misconceptions is required to prevent stigmatization of patients and carriers. Most migrants failed to identify thalassemia as a serious chronic condition and a common disease in Asia, which may detract from the perceived importance and urgency of screening. The fact that many Thai subjects held these same misconceptions highlights existing gaps in Thailand's thalassemia education program that should be addressed.

All nationalities, in particular Cambodians, expressed a strong interest in the concept of thalassemia screening. However, migrants expressed more negative attitudes towards pregnancy termination, which might preclude the prenatal approach to thalassemia prevention in migrants. The surveys were not designed to elucidate reasons underlying migrants' attitudes towards pregnancy termination; these themes should be explored in greater depth using qualitative methods, such as in-depth interviews and focus group discussions. On the other hand, our study had extremely high uptake (96.9\%) of thalassemia screening by healthy migrant subjects, strongly suggesting that carrier screening would be acceptable to migrants.

Our health registration-based approach to thalassemia screening represents a unique and particularly efficient means of recruiting both documented and undocumented migrants. We found that public hospitals were a feasible, convenient setting for performing thalassemia screening but not for the return of results. An alternative setting that overcomes some structural barriers is the workplace, though privacy concerns and the willingness of employers to participate would need to be considered. Our study design has some limitations; survey results and thalassemia allele frequencies obtained from migrant workers presenting to $\mathrm{LCH}$ may not be representative of other migrant populations in Thailand. Indeed, we previously demonstrated spatial specificity in the gene frequency of $\alpha$-thalassemia in Thailand [27]. A similar geographic limitation may exist for the Thai community cohort undergoing thalassemia testing. The Thai cohort presenting to $\mathrm{LCH}$ is likely representative of the majority of the Thai population, which utilizes public health services due to the availability of universal health coverage in Thailand. However, individuals using the private health sector may differ in socioeconomic status and may not be represented in our cohorts. Additionally, due to the extremely low level of thalassemia awareness among migrants, only 11 migrant subjects completed the KAP survey, compared to 155 Thai subjects. The limited KAP survey data from migrants made drawing comparisons challenging and further subset analyses impossible. Ideally, our findings would be confirmed using a larger representative sample of migrants, employing either a multicenter approach or with comparisons to SEA migrant populations residing in other host countries.

Nevertheless, this study highlights the dramatic gap in thalassemia awareness between Thai citizens and migrants and the urgent need for public educational interventions accessible to migrants. Furthermore, we developed a multilingual KAP survey with face validity and acceptable reliability for assessing thalassemia knowledge and attitudes across three different nationalities (see Additional file 1). This thalassemia-specific KAP survey should be further validated in future studies for use as a multinational tool in SEA populations worldwide.

Finally, our data confirm the high prevalence of thalassemia among migrants in Thailand, laying the foundation for additional epidemiological and cost-effectiveness studies needed to inform future policy decisions surrounding thalassemia prevention and control. The projected annual number of migrant newborns affected by severe thalassemia is likely an underestimate, due to 
unregistered migrant populations being unaccounted for in official migration statistics, demonstrating the need for regularization of the migrant workforce to create effective public health policies.

\section{Conclusions}

In this study, we developed a knowledge, attitudes, and practices (KAP) survey focused on thalassemia screening and validated the survey in healthy Myanmar, Cambodian, and Thai populations. We also offered comprehensive thalassemia testing to all migrant subjects and found that thalassemia is prevalent among Myanmar and Cambodian migrants and that nearly all migrants were willing to undergo thalassemia screening. However, we identified an extreme lack of awareness and understanding of thalassemia in migrant compared to Thai populations, as well as identified key misconceptions in both migrant and Thai populations that need to be addressed. Based on the KAP survey results, we conclude that lack of awareness of thalassemia is a prominent obstacle to thalassemia screening in migrant populations in Thailand and that public education efforts tailored to migrant populations are desperately needed. The negative attitudes towards termination of pregnancy among migrants suggest that Thailand's prenatal approach to thalassemia screening may not be optimal for migrant populations and that other potential screening approaches should be explored. Indeed, we found carrier screening among migrant workers to be highly feasible and acceptable. Furthermore, the high frequencies of thalassemia variants identified in our migrant cohort argue strongly for the inclusion of migrant populations in thalassemia prevention and control policies in Thailand as well as regionally.

With increasing economic integration and cooperation among the ASEAN (Association of Southeast Asian Nations) member countries, intra-regional migration will continue to grow. The scientific community, healthcare providers, and policymakers must recognize the challenges posed by migration to regional thalassemia prevention and control and respond accordingly. Concerted efforts should be made not only to establish regional thalassemia screening programs and registries but also to extend thalassemia services to migrants within the region. With continued investigation into knowledge, cultural, and structural barriers to thalassemia prevention in migrant populations, we may begin to create a global solution for the growing public health problem of thalassemia.

\section{Abbreviations}

KAP: Knowledge, Attitudes, and Practices; Hb: Hemoglobin; SEA: Southeast Asia; LCH: Laem Chabang Hospital; IQR: Inter-quartile ranges; SAS: Statistical Analysis Software; NC: North Carolina; USA: United States of America; CBC: Complete blood count; HPLC: High-performance liquid

chromatography; PCR: Polymerase chain reaction; NA: Not available; CI: 95\% confidence interval; ASEAN: Association of Southeast Asian Nations; NT: Not tested; CS: Constant Spring; PS: Pakse; QZ: Quang Sze; WM: Westmead

\section{Supplementary Information}

The online version contains supplementary material available at https://doi. org/10.1186/s12889-021-11059-2.

Additional file 1. Survey tools for thalassemia, Demographic and KAP surveys developed for this study are provided in English, Thai, Burmese, and Khmer languages.

\section{Acknowledgments}

We would like to thank all the subjects for participating in this study; Miss Nattina Khiewon, Mrs. Chintana Phannetr, and other Laem Chabang Hospital staff for their assistance with conducting surveys; and Drs. Chaninart Phongsri, Chanvorleak Nhem, Tin Nilar Win Kywe, and Htein Lin for their translation support.

\section{Authors' contributions}

JZX: Literature search, study design, data collection, laboratory testing, data analysis, data interpretation, and writing. WT: Study design, data collection, and data interpretation. TS: Study design, data collection, and laboratory testing. SE: Study design, laboratory testing, data analysis, data interpretation, and writing. SR: Data collection, laboratory testing, data analysis, and data interpretation. MJT: Study design, data interpretation, and writing. W: Study design, data collection, laboratory testing, data interpretation, and writing. All authors read and approved the final manuscript.

\section{Funding}

JZX was supported by the NIH/Fogarty International Center Global Health Research Fellowship (2D43TW009337-07), the Cooley's Anemia Foundation Research Fellowship, the American Society of Hematology HONORS Award, and the Duke Global Health Institute, Hubert-Yeargan Center for Global Health, and Department of Medicine. W, SE, and TS were supported by the Research Excellent Development (RED) program, Faculty of Medicine Siriraj Hospital, Mahidol University, Bangkok, Thailand. The funding bodies did not play any role in the design of the study and collection, analysis, and interpretation of data and in writing the manuscript. Open Access funding provided by the National Institutes of Health $(\mathrm{NIH})$.

Availability of data and materials

The datasets generated and/or analyzed during the current study are available from the corresponding authors on reasonable request.

\section{Declarations}

\section{Ethics approval and consent to participate}

This study's protocol conformed to the Helsinki Declaration and was approved by LCH leadership and by ethical review boards at Duke University (IRB Protocol \# Pro00082655) and Mahidol University (SIRB Protocol \# 729/ 2560(EC3)). Written informed consent was obtained from all participants after careful explanation of the purpose, methods, and voluntary nature of this study.

\section{Consent for publication}

Not applicable.

\section{Competing interests}

The authors declare that they have no competing interests.

\section{Author details}

${ }^{1}$ Department of Medicine, Duke University, Durham, USA. ${ }^{2}$ National Heart, Lung, and Blood Institute, National Institutes of Health, 10 Center Drive, MD 20892 Bethesda, USA. ${ }^{3}$ Department of Pediatrics, Laem Chabang Hospital, Laem Chabang, Chonburi 20230, Thailand. "Thalassemia Center, Faculty of Medicine Siriraj Hospital, Mahidol University, 2 Wanglang Road, Bangkoknoi, Bangkok 10700, Thailand. ${ }^{5}$ Department of Pediatrics, Faculty of Medicine Siriraj Hospital, Mahidol University, 2 Wanglang Road, Bangkoknoi, Bangkok 10700, Thailand. ${ }^{6}$ Thalassemia Center and Department of Pediatrics, Faculty 
of Medicine Siriraj Hospital, Mahidol University, 2 Wanglang Road, Bangkoknoi, Bangkok 10700, Thailand.

Received: 18 February 2021 Accepted: 10 May 2021

Published online: 21 June 2021

\section{References}

1. Weatherall DJ, Williams TN, Allen SJ, O'Donnell A. The population genetics and dynamics of the thalassemias. Hematol Oncol Clin North Am. 2010; 24(6):1021-31. https://doi.org/10.1016/j.hoc.2010.08.010.

2. Angastiniotis $M$, Vives Corrons $J$, Soteriades ES, Eleftheriou A. The impact of migrations on the health services for rare diseases in Europe: the example of haemoglobin disorders. ScientificWorldJournal. 2013; 2013:727905.

3. Aguilar Martinez $P$, Angastiniotis M, Eleftheriou A, Gulbis B, Manu Pereira Mdel M, Petrova-Benedict R, et al. Haemoglobinopathies in Europe: health \& migration policy perspectives. Orphanet J Rare Dis. 2014;9:97.

4. Vichinsky EP. Changing patterns of thalassemia worldwide. Ann N Y Acad Sci. 2005;1054(1):18-24. https://doi.org/10.1196/annals.1345.003.

5. Weatherall DJ, Clegg JB. Inherited haemoglobin disorders: an increasing global health problem. Bull World Health Organ. 2001;79(8):704-12.

6. Fucharoen S, Weatherall DJ. Progress toward the control and Management of the Thalassemias. Hematol Oncol Clin North Am. 2016;30(2):359-71. https://doi.org/10.1016/j.hoc.2015.12.001.

7. Ismail JB. Thalassaemia and haemoglobinopathies in Brunei Darussalam. Med J Malaysia. 1992;47(2):98-102.

8. Savongsy O, Fucharoen S, Fucharoen G, Sanchaisuriya K, Sae-Ung N. Thalassemia and hemoglobinopathies in pregnant Lao women: carrier screening, prevalence and molecular basis. Ann Hematol. 2008;87(8):647-54. https://doi.org/10.1007/s00277-008-0490-z.

9. Wongprachum K, Sanchaisuriya K, Dethvongphanh M, Norcharoen B, Htalongsengchan B, Vidamaly $V$, et al. Molecular heterogeneity of thalassemia among pregnant Laotian women. Acta Haematol. 2016;135(2): 65-9. https://doi.org/10.1159/000438739.

10. Viprakasit V, Lee-Lee C, Chong QT, Lin KH, Khuhapinant A. Iron chelation therapy in the management of thalassemia: the Asian perspectives. Int J Hematol. 2009;90(4):435-45. https://doi.org/10.1007/s12185-009-0432-0.

11. Wanapirak C, Tongsong T, Sirivatanapa P, Sa-nguansermsri T, Sekararithi R, Tuggapichitti A. Prenatal strategies for reducing severe thalassemia in pregnancy. Int J Gynaecol Obstet. 1998;60(3):239-44. https://doi.org/10.101 6/S0020-7292(97)00271-3.

12. United Nations Department of Economic and Social Affairs Population Division. Trends in International Migrant Stock 2015. http://www.un.org/en/ development/desa/population/migration/publications/migrationreport/ docs/migration-regions-infographics.pdf. Accessed 8 Oct 2016.

13. Huguet JW, Chamratrithirong A. Thailand migration report 2011. Bangkok: International Organization for Migration; 2011.

14. Weatherall DJ. Thalassemia as a global health problem: recent progress toward its control in the developing countries. Ann N Y Acad Sci. 2010; 1202(1):17-23. https://doi.org/10.1111/j.1749-6632.2010.05546.x.

15. Chattopadhyay S. 'Rakter dosh'--corrupting blood: the challenges of preventing thalassemia in Bengal, India. Soc Sci Med. 2006;63(10):2661-73. https://doi.org/10.1016/j.socscimed.2006.06.031.

16. Nidorf JF, Ngo KY. Cultural and psychosocial considerations in screening for thalassemia in the southeast Asian refugee population. Am J Med Genet. 1993;46(4):398-402. https://doi.org/10.1002/ajmg.1320460411.

17. Romeo MA, Di Gregorio F, Russo G. Persistence of Mediterranean anaemia in Sicily. J Med Genet. 1997;34(10):869-70. https://doi.org/1 0.1136/jmg.34.10.869.

18. Basu M. A study on knowledge, attitude and practice about thalassemia among general population in out patient Department at a Tertiary Care Hospital of Kolkata. J Prev Med Holistic Health. 2015;1(1):5-12.

19. Khin Ei H, Aung Myo H, Thein Thein M. Thalassemia in the outpatient department of the Yangon Children's Hospital in Myanmar: knowledge, attitudes and practice in relation to thalassemia. Southeast Asian J Trop Med Public Health. 1992;23(2):269-72.

20. Miri-Moghaddam E, Motaharitabar E, Erfannia L, Dashipour A, Houshvar M. High school knowledge and attitudes towards thalassemia in southeastern Iran. Int J Hematol Oncol Stem Cell Res. 2014;8(1):24-30.
21. Wong LP, George E, Tan JA. Public perceptions and attitudes toward thalassaemia: influencing factors in a multi-racial population. BMC Public Health. 2011;11(1):193. https://doi.org/10.1186/1471-2458-11-193.

22. Pauisri S, Saksiriwuttho $P$, Ratanasir T. Knowledge and attitude of pregnant women at risk for having a fetus with severe thalassemia after genetic counseling at Srinagarind hospital. Thai J Obstetr Gynaecol. 2011;19(4):193-9.

23. Armeli C, Robbins SJ, Eunpu D. Comparing knowledge of beta-thalassemia in samples of Italians, Italian-Americans, and non-Italian-Americans. J Genet Couns. 2005;14(5):365-76. https://doi.org/10.1007/s10897-005-1123-5.

24. Viprakasit V, Ekwattanakit S, Riolueang S, Chalaow N, Fisher C, Lower K, et al. Mutations in Kruppel-like factor 1 cause transfusion-dependent hemolytic anemia and persistence of embryonic globin gene expression. Blood. 2014; 123(10):1586-95. https://doi.org/10.1182/blood-2013-09-526087.

25. Riolueang S, Ekwattanakit S, Korchuenjit J, Korchuenjit W, Tanyut P, Clark B, et al. Identification of a novel alpha0-thalasssemia (SIAM; --SIAM), a rare $239 \mathrm{~kb}$ deletion of the alpha-globin cluster and the molecular application from routine DNA testing to prenatal diagnosis (PND) and preimplantation genetic diagnosis (PGD). Chiang Rai: 24th National Thalassemia Conference; 2019.

26. Hardy GH. Mendelian proportions in a mixed population. Science. 1908; 28(706):49-50. https://doi.org/10.1126/science.28.706.49.

27. Hockham C, Ekwattanakit S, Bhatt S, Penman BS, Gupta S, Viprakasit V, et al. Estimating the burden of alpha-thalassaemia in Thailand using a comprehensive prevalence database for Southeast Asia. Elife. 2019;8. https:// doi.org/10.7554/eLife.40580.

28. United Nations. World population prospects 2019. https://esa.un.org/unpd/ wpp/. Accessed 8 Jan 2020.

29. Thai Foreign Worker Administration Office. Statistical Data of Migrant Workers. https://www.doe.go.th/prd/alien/statistic/param/site/152/cat/82/ sub/0/pull/module/view/list-label. Accessed 22 Jan 2020.

30. Shotelersuk V, Limwongse C, Mahasirimongkol S. Genetics and genomics in Thailand: challenges and opportunities. Mol Genet Genomic Med. 2014;2(3): 210-6. https://doi.org/10.1002/mgg3.83.

31. Fucharoen S, Tanphaichitr VS, Torcharus K, Viprakasit V, Meekaewkunchorn A. Thailand clinical practice guidelines for diagnosis and management of thalassemia syndromes. Bangkok: Queen Sirirkit National Institute of Child Health; 2014.

32. Modell B, Darlison M. Global epidemiology of haemoglobin disorders and derived service indicators. Bull World Health Organ. 2008;86(6):480-7. https://doi.org/10.2471/blt.06.036673.

33. Low WY, Tong WT, Binns C. Migrant Workers in Asia Pacific and Their Rights to health. Asia Pac J Public Health. 2015;27(6):584-7. https://doi.org/10.11 77/1010539515600007.

\section{Publisher's Note}

Springer Nature remains neutral with regard to jurisdictional claims in published maps and institutional affiliations.

\section{Ready to submit your research? Choose BMC and benefit from:}

- fast, convenient online submission

- thorough peer review by experienced researchers in your field

- rapid publication on acceptance

- support for research data, including large and complex data types

- gold Open Access which fosters wider collaboration and increased citations

- maximum visibility for your research: over $100 \mathrm{M}$ website views per year

At BMC, research is always in progress.

Learn more biomedcentral.com/submissions 